\title{
Preference for and Efficacy of a PrEP Decision Aid for Women with Substance Use Disorders
}

\author{
Jaimie Meyer $\mathbb{B}^{1,2}$ \\ Carolina Price ${ }^{\prime}$ \\ DeShana Tracey \\ Laurel Sharpless $\mathbb{D}^{2}$ \\ Yue Song ${ }^{2,3}$ \\ Lynn Madden (D) ${ }^{1,4}$ \\ Glyn Elwyn ${ }^{5-7}$ \\ Frederick Altice (D) 1,2,4,8 \\ 'Yale School of Medicine, AIDS Program, \\ New Haven, CT, USA; ${ }^{2}$ Yale School of \\ Public Health, New Haven, CT, USA; \\ ${ }^{3}$ Oregon Health Sciences University, \\ Portland, OR, USA; ${ }^{4}$ APT Foundation, \\ Inc., New Haven, CT, USA; ${ }^{5}$ The \\ Dartmouth Institute for Health Policy \\ and Clinical Practice, Hanover, NH, USA; \\ ${ }^{6}$ Scientific Institute for Quality of \\ Healthcare, University Nijmegen Medical \\ Centre, Nijmegen, Netherlands; \\ ${ }^{7}$ Cochrane Institute for Primary Care and \\ Public Health, Cardiff University, Cardiff, \\ UK; ${ }^{8}$ Centre of Excellence on Research \\ in AIDS (CERiA), University of Malaya, \\ Kuala Lumpur, Malaysia
}

Background: Women with substance use disorders (SUDs) are a key population for HIV prevention with pre-exposure prophylaxis (PrEP), though uptake is limited by awareness of PrEP, misestimation of personal HIV risk, and minimally integrated HIV prevention and addiction treatment services. Patient-centered decision aids (DA) could address these barriers to PrEP, but no extant DA for PrEP has been published, including for women with SUDs.

Methods: We developed a patient-centered PrEP DA for women in addiction treatment. In a pilot randomized preference trial, we compared the DA to enhanced standard of care (eSOC) providing standardized information. The primary outcome was opting to receive more information through the DA; we also assessed the impact of the DA on PrEP decisional preference and PrEP uptake over 12 months.

Results: A total of 164 enrolled participants (DA: 83; eSOC: 81) were similar in terms of HIV risk and demographics, which are representative of women in addiction treatment programs nationally, and most $(92 \%)$ had opioid use disorder. Half of participants were PrEP eligible, though 37\% underestimated their personal HIV risk. Independent correlates of selecting the PrEP DA relative to eSOC included higher alcohol use severity (aOR 4.13, 95\% CI 1.05-16.28, $p=0.04$ ) and perception of high risk for HIV (aOR 2.95, 95\% CI 1.19-7.35, $p=0.02$ ). For those selecting the DA, interest in PrEP increased significantly from $25 \%$ to $89 \%$. DA participants were also significantly more likely than eSOC participants to see a provider for PrEP during follow-up ( $15.7 \%$ vs $6.2 \%$; $p=0.05)$.

Conclusion: Half of the women selected to use the DA, and those who did significantly increased their engagement in the HIV prevention cascade through increased interest in and initiation of PrEP. Future iterations should accelerate the HIV prevention cascade for women with SUDs by integrating PrEP decision aids into existing addiction treatment services and actively linking women to PrEP.

Keywords: PrEP, women, substance use disorders, decision aids

\section{Plain Language Summary}

Why was this study done? Women with substance use disorders are at high risk for HIV and could benefit from pre-exposure prophylaxis (PrEP) for HIV prevention but are often unaware of it or unable to access it. The purpose of this study was to design and test a tool to help women make informed decisions about PrEP.

What did the researchers do and find? We developed a decision aid about PrEP to meet women's needs and recruited 164 women with substance use disorders who were in treatment into a clinical trial. Women could choose to receive more information about PrEP through the decision aid or not choose to receive more information about PrEP (and instead receive a generic pamphlet that is enhanced standard of care). The decision aid successfully increased women's 
interest in PrEP for those who received it and was associated with an increased chance of initiating PrEP by 12 months.

What do these results mean? The decision aid helped to change women's minds about PrEP, especially those at highest risk for HIV, and was associated with starting PrEP, even though we did not directly link them to care as part of the study.

\section{Introduction}

Each year in the US, one in five new HIV infections occur in women. ${ }^{1}$ Although most (87\%) HIV infections among US women are attributable to heterosexual sex, substance use is often involved, ${ }^{1}$ which in turn increases sexual risktaking and decreases risk perception, even at nondisordered levels. ${ }^{2-4}$ Women with substance use disorders (SUDs) are a designated high priority population for targeted evidence-based HIV prevention that is central to the US strategy for Ending the HIV Epidemic (EHE). ${ }^{5-7}$

HIV pre-exposure prophylaxis (PrEP) scale-up is one of the four pillars of EHE. ${ }^{7}$ PrEP has transformed the prevention landscape for women because, before PrEP, HIV biomedical prevention interventions that were effective at preventing HIV still required a male partner's cooperation. In contrast, PrEP is event-independent, usercontrolled, and partner-independent. ${ }^{8}$ A woman-controlled HIV prevention strategy, like oral contraceptives for pregnancy prevention, is critical for women who are violence-exposed, dependent on partners for basic subsistence, and have limited autonomy to negotiate condoms or select sex partners. ${ }^{9-11}$ Behavioral interventions alone ${ }^{8}$ are insufficient to reduce women's HIV risk because they do not address other conditions (such as intimate partner violence, SUDs, and psychiatric disorders) or relationships that affect women's risk. PrEP thereby empowers women $^{12,13}$ and has proven effective in preventing HIV in some trials of heterosexual sero-discordant couples when adherence is optimized, especially when combined with "treatment as prevention" for the partner living with HIV. ${ }^{14-17}$ Mathematical modeling suggests optimal PrEP coverage in a largely heterosexual epidemic could reduce new infections by up to $39 \%$ over 10 years. ${ }^{18}$ In the Bangkok Tenofovir Trial, the only randomized clinical trial of PrEP for people who inject drugs (PWID), tenofovir was associated with a $79 \%$ reduction in HIV acquisition compared to placebo among the 489 women enrolled. ${ }^{19,20}$

In real-world settings, women's PrEP use is consistently limited by: 1) lack of awareness that PrEP is an effective prevention strategy; ${ }^{21}$ and 2) misestimation of personal HIV risk, especially among women with SUDs. $^{22-28}$ Since TDF/FTC (Truvada ${ }^{\circledR}$ ) was FDAapproved for PrEP in 2012, fewer than 5\% of US women meeting clinical criteria have received it, and they are disproportionately non-Hispanic White, which does not demographically reflect the HIV epidemic among women. $^{29-31}$

The current study aims to address deficits in PrEP scale-up $^{22}$ for women with SUDs by empowering them to make informed choices about effective HIV prevention options, including PrEP. In response to a call for patientled decision-making interventions on PrEP, ${ }^{32}$ we developed and tested an informed, patient-centered decision aid (DA) on PrEP for women in addiction treatment. In contrast to generalized information-education-counselling approaches, patient-centered DAs convey specific and value-congruent personal health options, thereby encouraging active consumer participation. ${ }^{33}$ To our knowledge, to date, there have been no published DAs for PrEP for HIV prevention and none tailored to women with SUD. ${ }^{32,34,35}$

\section{Methods}

\section{Study Setting}

The study, known as OPTIONS (registered as NCT03651453 on Clinicaltrials.gov), was conducted at Connecticut's largest addiction treatment center, which provides comprehensive services including primary care, both ambulatory and residential treatment, and medications for opioid use disorder (MOUD). Across four sites with an open access policy, ${ }^{36}$ there are approximately 300 new intakes per month, one-third of whom are women. HIV testing is offered at intake and PrEP is available for patients who request it through onsite primary care.

We integrated data from individual semi-structured qualitative interviews, focus groups, workshops and topical experts to develop a DA for PrEP tailored to women enrolled in addiction treatment. The development processes occurred between December 2017 and September 2018 and qualitative findings are described elsewhere. ${ }^{37}$ The final DA was reviewed for adherence to International Patient Decision Aids Standards (IPDAS). ${ }^{38}$ The elements of the DA involved a discussion on the pros and cons of using PrEP relative to other prevention strategies, addressing domains identified as important to women with SUDs, including PrEP's efficacy, cost, side effects, medication interactions, insurance coverage, and need for disclosure to partners. 


\section{Recruitment and Study Sample}

Participants were recruited to the study from the treatment program by trained research assistants. Treatment program staff also provided a list of clients who expressed general interest in participating in clinical research; the research team contacted these individuals directly to describe the study and screen for eligibility. Addiction treatment staff could directly refer clients. Promotional material was also available throughout the facilities, allowing clients to self-refer to the study using a HIPAA-secure Qualtrics link or a dedicated study phone line.

Members of the research team screened all interested women in a private space for the following eligibility criteria: self-identification as female (ie, cis- or transwomen), age $\geq 18$, self-reported HIV-uninfected or status unknown, and entering or receiving addiction treatment. Individuals were excluded if they were unable or unwilling to provide written informed consent, experiencing physiologic symptoms of withdrawal that could interfere with their ability to provide informed consent, participated in formative phases of the project (to minimize selection bias), or were already on PrEP or enrolled in other PrEPrelated research studies. All participants provided written informed consent and signed a release of information form to access the electronic health record (EHR) and other quality improvement data at the addiction treatment clinic. All procedures were approved by the institutional review board at Yale University and the Board of Directors at the treatment program. The study was conducted in accordance with the Declaration of Helsinki.

\section{Intervention Delivery}

Enrollment occurred between October 2018 and October 2019. After consent procedures, study interviews were conducted in English or Spanish by a trained researcher using RedCAP. During the baseline interview, participants were provided with a brief description of PrEP as an "HIV prevention pill" and asked, do you want to learn more about PrEP? Those who answered affirmatively were preferentially assigned to engage with the DA. Those selecting not to receive more information were assigned to receive an enhanced standard of care (eSOC). The rationale for using a natural preference design, rather than randomization, was to more precisely reflect individualized decision-making processes in "real world" settings, where individuals often need different types of support and information to make decisions. We were interested in understanding who, when, and how individuals needed support to make choices about PrEP. Participants who opted into the "more information" DA arm engaged with the DA through a client-facing screen on RedCAP in the presence of a trained research assistant. Enhanced standard of care (eSOC) involved providing a phone number and website for more information about HIV prevention and where PrEP could be accessed, without any additional personalized assessment or coaching. This is more than the information about PrEP that is typically provided in addiction treatment settings. There was no intervention to actively link participants to PrEP clinical services or directly provide PrEP to participants in either arm.

\section{Study Assessments and Data Extraction}

All study interviews were conducted using RedCAP in a private room and used standardized instruments in English or Spanish at baseline and quarterly for 12 months. Participants were paid $\$ 20$ for the baseline and $\$ 5$ for the brief, quarterly follow-up interviews, done in person or by phone or text depending on participant preference.

The EHR in the treatment program was manually reviewed using a standardized chart abstraction tool for active current substance use and psychiatric disorder diagnoses using ICD-10 codes, and testing dates and results for HIV and Hepatitis C (HCV). A linked treatment center database was then electronically queried for quality improvement measures, which are collected at treatment center admission for all patients for program planning purposes and to characterize the population (as is being done here). Quality improvement measures included the life events checklist (LEC-5), ${ }^{39}$ Behavior and Symptom Identification Scale, Adult version (BASIS-24), ${ }^{40}$ and Generalized Self-Efficacy scale. ${ }^{41}$ All extracted data were merged into the RedCAP database.

\section{Measures}

The primary outcome, and the first decision point in the HIV prevention cascade, was opting for "more information" via the DA, the measurement of and rationale for which is described above. We also assessed the efficacy of the DA in terms of modifying the decisional preference for PrEP at baseline for both groups using the 5-point Likert scale question: Would you take PrEP if it were available to you? Responses were analyzed continuously and categorized into 3 groups: 1) No; 2) Unsure, I do not know what PrEP is, or Maybe but I need more information; and 3) Yes and I am ready to start immediately or Yes but not right now. 
Immediately after completing the DA, DA-selecting participants were asked, Now that you have learned more about PrEP, how likely are you to use it? Responses were given on a 5-point Likert scale and assessed as an ordinal variable and dichotomized as likely versus unlikely. Participants were then asked to select which information presented in the DA contributed most to their decision about PrEP. Perception of HIV risk was determined at baseline and quarterly thereafter by the question, How likely are you to become infected with HIV? and assessed on a 5-point Likert scale from Not at all likely to Extremely likely. Scores were analyzed both categorically and continuously.

An exploratory efficacy outcome, PrEP uptake, was assessed at 3-, 6-, 9- and 12-month post-enrollment and operationalized as self-reporting a clinical visit with a provider for the purposes of starting PrEP. Pharmacy or clinic data were not available for verification; all PrEP engagement was self-reported.

Demographic and social characteristic variables included marital status, which was categorized as currently married or not married (ie widowed, separated, divorced, or never married.) Housing status was categorized as "usual" living arrangements over the past 3 years and past 30-days (in a house or apartment, unstable or transitional, controlled setting). Healthcare engagement was measured as time since "last checkup by a primary care provider" and dichotomized at one year.

Substance use severity was assessed using the drug subscale on the Addiction Severity Index (ASI-D); scores were assessed continuously and dichotomized at pre-specified validated cutoffs for severe alcohol $(\geq 0.17)$ and drug $(\geq 0.12)$ use. $^{42,45}$ Alcohol use severity was also evaluated at baseline using the World Health Organization's Alcohol Use Disorders Identification Test (AUDIT), ${ }^{43}$ with harmful or hazardous drinking for women defined as scores $\geq 4{ }^{44}$ Substance use disorder diagnoses from the EHR included alcohol, opioid, and cocaine use disorders.

Psychiatric disorders were evaluated at baseline using the psychiatric subscale of the ASI (ie, ASI-P) as a continuous score with severe lifetime psychiatric disorders dichotomized at $0.22{ }^{45}$ The following psychiatric disorder diagnoses were extracted from the EHR: bipolar disorder, anxiety disorder, post-traumatic stress disorder (PTSD), and major depressive disorder. Lifetime trauma was assessed by the LEC-5, ${ }^{39}$ including personally experiencing: 1) physical assault (being attacked, hit, slapped, kicked, beaten up); 2) assault with a weapon (being shot, stabbed, threatened with a knife, gun, bomb); or 3) sexual assault (rape, attempted rape, made to perform any type of sexual act through force or threat of harm). Behavioral health was assessed by the BASIS- $24^{40}$ to evaluate functioning within the past week along various domains; each item is scored on a Likert scale from 0 to 4 , with higher scores indicating more extreme difficulty. Self-efficacy was measured by the 10-item Generalized Self-Efficacy Scale, ${ }^{41}$ with each item on a Likert scale from 1 (not at all true) to 4 (exactly true), with sum scores ranging from 10 to 40 .

HIV risk was evaluated using standard measures of sex and drug risk from NIDA's modified risk behavior assessment $^{46}$ and adjusted to include CDC-based clinical eligibility criteria for PrEP. ${ }^{47}$ Participants were asked at baseline about whether they had engaged in any of the following behaviors within the prior 6 months: 1) condomless sex with a high-risk partner (ie, a man with HIV who was not on treatment, a man with unknown HIV status, a man who injected drugs, or while intoxicated); 2) injection drug use and sharing any injecting equipment; 3) transactional sex (defined as the exchange of sex for drugs, money, goods, or other services); or 4) diagnosed with a bacterial sexually transmitted infection. We assessed the total number of different HIV risk behaviors reported for each individual. At each follow-up visit, participants were asked about interim 3-month HIV risk behaviors. PrEP eligibility was determined by current clinical guidelines. ${ }^{48}$ We calculated risk underestimation as being eligible for PrEP (and therefore having a high HIV risk) but perceiving a low HIV risk. We evaluated whether participants had ever had HIV and HCV testing recorded in the EHR, and associated results.

\section{Statistical Analysis}

Descriptive statistics were used to characterize the study sample, comparing those who opted into the DA to those who received eSOC, using Chi-squared or Fisher's exact tests for categorical variables and independent Student's $t$-test for continuous variables. The purpose of the comparative analysis was to assess for differences in participants who opted in or out of requesting more information from the DA, which is important for understanding this first decision step as an outcome. We used logistic regression to model the primary outcome of interest with more information, ie, opting for the DA. After assessing bivariate associations between demographic or clinical factors and the primary outcome, a parsimonious logistic regression model was developed that included bivariate associations significant at $p<0.2$ Based on goodness-of-fit testing, the BASIS-24 relationship domain 
was excluded from the multivariate model for collinearity with social support. We used paired $t$-tests to compare mean PrEP interest before and after the DA for those selecting the DA. We used descriptive statistics to assess longitudinal PrEP outcomes by the study arm. Statistical significance was defined as $p<0.05$ All analyses were conducted using SAS version 9.4 (SAS Institute Inc., Cary, NC, USA).

\section{Results}

Among the 216 women with SUD assessed for study eligibility, $164(75.9 \%)$ were enrolled after excluding 12 for not meeting study criteria and 40 for inability to contact them or other logistical reasons (Figure 1). Among those enrolled $(\mathrm{N}=164), 83$ selected more information using the DA and 81 chose eSOC. After 3 months, study retention was similar in the DA and eSOC arms ( $82 \%$ versus $73 \% ; p=0.16$ ). Moreover, there were no significant differences in demographic or clinical characteristics of participants missing versus not missing at any time point over the 12 months of follow-up.

The sample (Table 1) was demographically representative of women in addiction treatment locally and nationally. ${ }^{49}$ Women were, on average, 40.4 years old, with the majority being non-Hispanic and white. Many had a high-school education, were unemployed, housed, and had seen a healthcare provider within the past year (79.9\%). Most participants (92.1\%) had opioid use disorder and over half met criteria for severe substance use. Fewer women were diagnosed with alcohol use disorder recorded in the EHR $(14.0 \%)$ relative to those who screened positive for hazardous drinking using the AUDIT (31.7\%). Psychiatric disorders were also highly prevalent in the sample, with approximately one-third having been diagnosed with anxiety, post-traumatic stress, and/or major depressive disorders. An even higher proportion of participants experienced lifetime trauma that

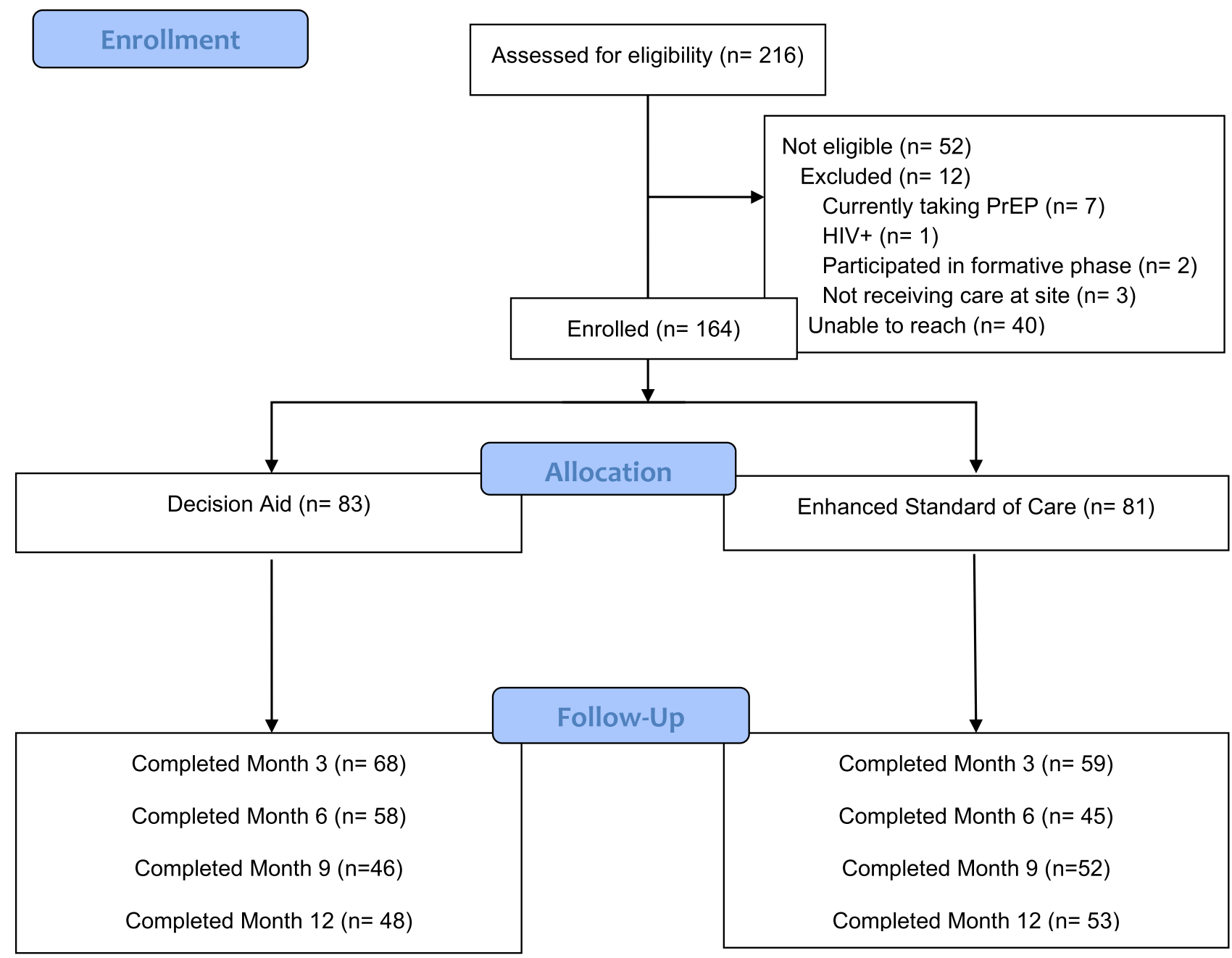

Figure I CONSORT Flow Diagram of Participant Allocation. 


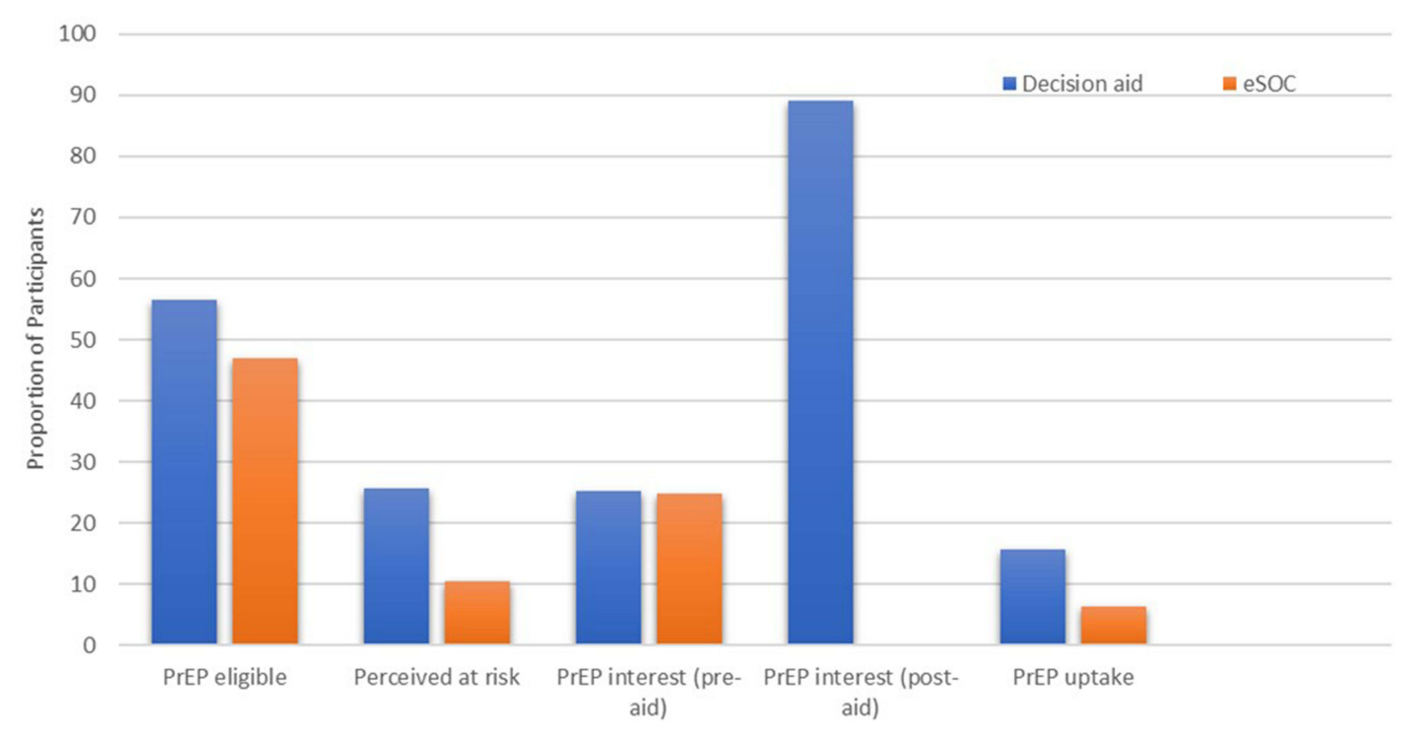

Figure 2 Longitudinal PrEP Outcomes by Study Arm ( $\mathrm{N}=164)$.

Abbreviation: eSOC, enhanced standard of care.

included physical and sexual assaults. Daily functioning was negatively impacted by depression, emotional lability, and substance use, as reflected in high BASIS-24 scores in each of these domains. Criminal justice involvement was also relatively high in the cohort overall. Women experienced a mean 3.8 (SD 8.8) of lifetime arrests and mean 9.6 months (SD 29.3) of lifetime incarceration; there were no significant differences between the two arms in terms of these factors.

DA participants had significantly higher lifetime alcohol use severity relative to the eSOC group (13.3\% v. $3.7 \%, p=0.03$; Table 1 ). Although not statistically significant, we also observed differences in relationship measures between the two arms in that participants in the DA arm had relatively higher (ie, more disruptive) relationship scores on the BASIS-24 and lower overall social support scores. Otherwise, there were no observed differences between the DA and eSOC groups in terms of demographic or clinical factors.

Though not shown in Tables 1, 70 participants (42.7\%) had completed recent HIV testing (all were HIV negative). Overall, 76 (46.3\%) had completed HCV testing, of whom 30 screened positive for HCV antibody, and 6 had detectable HCV RNA, indicating untreated chronic HCV infection. Completion of HIV or HCV testing did not differ by study arm, though among participants with a positive HCV antibody, DA participants more often had undetectable HCV RNA levels, suggesting treated or spontaneously cleared infection.
Table 2 presents HIV risk and PrEP interest by study arm. Baseline risk behaviors were common at baseline, including recent condomless sex (73.9\%), injection drug use $(32.1 \%)$, transactional sex $(9.7 \%)$, and recently diagnosed sexually transmitted infections $(6.1 \%)$, resulting in over half $(52 \%)$ of the overall sample meeting PrEP eligibility criteria. There were no significant differences between the two arms in terms of HIV risk behaviors or PrEP eligibility, though DA participants were significantly more likely to have a higher perceived risk for acquiring HIV (25.6\% vs $10.4 \%$; $p=0.01)$. Baseline interest in PrEP was marginally higher in the DA arm $(25.3 \%$ vs $24.7 \%)$, as was the ambivalence about taking PrEP (73.5\% vs $65.4 \%)$.

Table 3 depicts bivariate and independent correlates of selecting to receive more information using the DA. After controlling for other factors, the only two statistically significant correlates of selecting more information using the DA were alcohol use severity (aOR 4.13, 95\% CI $1.05-16.28, p=0.04)$ and high perceived risk for acquiring HIV (aOR 2.95, 95\% CI 1.19-7.35, $p=0.02$ ). Notably, PrEP eligibility and HIV risk underestimation were not associated with interest in receiving more information using the DA in the multivariate model.

We then turned to evaluating the effect of the DA on decisional preference for PrEP. Among the 83 women in the DA arm, interest in PrEP significantly increased from $25.3 \%$ to $89.2 \%$ after receiving the DA (Figure 2). This finding aligned with PrEP interest using the 5-point Likert 
Table I Baseline Characteristics of the Study Sample by Arm (N=164)

\begin{tabular}{|c|c|c|c|c|}
\hline Characteristic & Total Sample N= I 64 & Decision Aid $\mathbf{N}=83$ & eSOC $N=8$ I & $p$-value \\
\hline Mean age, SD & $40.4(10.3)$ & $40.4(10.4)$ & $40.4(10.3)$ & 0.96 \\
\hline Race & & & & 0.69 \\
\hline White & $123(75.0)$ & $62(74.7)$ & $61(75.3)$ & \\
\hline Black & $26(15.9)$ & $12(14.5)$ & $14(17.3)$ & \\
\hline Other & $15(9.2)$ & $9(10.8)$ & $6(7.4)$ & \\
\hline Ethnicity & & & & 0.84 \\
\hline Hispanic & $17(10.4)$ & $9(10.8)$ & $8(9.9)$ & \\
\hline Non-Hispanic & $147(89.6)$ & 74 (89.2) & $73(9.1)$ & \\
\hline Education completed & & & & 0.55 \\
\hline Less than high school & $31(18.9)$ & $18(21.7)$ & $13(16.1)$ & \\
\hline High school & $73(44.5)$ & $34(4 I .0)$ & $39(48.2)$ & \\
\hline More than high school & $60(36.6)$ & $31(37.4)$ & $29(35.8)$ & \\
\hline Median monthly income, IQR & $793(798)$ & $871(842)$ & $700(753)$ & 0.48 \\
\hline Employment Status & & & & 0.21 \\
\hline Full time & $74(15.1)$ & $32(38.6)$ & $42(51.9)$ & \\
\hline Part time & $37(22.6)$ & $20(24.1)$ & $17(21.0)$ & \\
\hline Retired/Disability & $17(10.4)$ & $12(14.5)$ & $5(6.2)$ & \\
\hline Unemployed & $36(22.0)$ & $19(22.9)$ & $17(21.0)$ & \\
\hline Marital status & $N=163$ & $N=83$ & $N=80$ & 0.21 \\
\hline Married & $36(22.1)$ & $15(18.1)$ & $21(26.3)$ & \\
\hline Not/never married & $127(77.9)$ & $68(81.9)$ & $59(73.8)$ & \\
\hline Past 3-year living arrangement & & & & 0.63 \\
\hline Alone & $18(11.0)$ & II (I3.3) & $7(8.6)$ & \\
\hline Controlled/Unstable & $14(8.5)$ & $6(7.2)$ & $8(9.9)$ & \\
\hline With family/friends/parents & $38(23.2)$ & $17(20.5)$ & $21(25.9)$ & \\
\hline With children/partner & $94(57.3)$ & $49(59.0)$ & $45(55.6)$ & \\
\hline Past $30 \mathrm{~d}$ housing status & $N=118$ & $N=61$ & $N=57$ & $0.37^{\mathrm{a}}$ \\
\hline House/apartment & $87(73.7)$ & $78(78.7)$ & $39(68.4)$ & \\
\hline Unstable/Transitional & $24(20.3)$ & $10(16.4)$ & $14(25.5)$ & \\
\hline Controlled setting & $7(5.9)$ & $3(4.9)$ & $4(7.0)$ & \\
\hline Last healthcare provider visit & & & & 0.91 \\
\hline Within past year & |3| (79.9) & $66(79.5)$ & $65(80.3)$ & \\
\hline More than I year prior & $33(20.1)$ & $17(20.5)$ & $16(19.8)$ & \\
\hline \multicolumn{5}{|l|}{ Mean Addiction Severity score, SD } \\
\hline Alcohol & $0.04(0.13)$ & $0.07(0.17)$ & $0.02(0.06)$ & 0.02 \\
\hline Drugs & $0.16(0.17)$ & $0.17(0.17)$ & $0.16(0.16)$ & 0.62 \\
\hline Severe lifetime alcohol use & $14(8.5)$ & II (I3.3) & $3(3.7)$ & $0.03^{\mathrm{a}}$ \\
\hline Severe lifetime drug use & $88(53.7)$ & $46(55.4)$ & $42(51.9)$ & 0.65 \\
\hline Hazardous drinking & $52(31.7)$ & $26(31.3)$ & $26(32.1)$ & 0.92 \\
\hline Mean Psychiatric Severity score, SD & $0.33(0.25)$ & $0.35(0.25)$ & $0.32(0.24)$ & 0.44 \\
\hline Severe lifetime psychiatric issue & III (67.7) & 57 (68.7) & $54(66.7)$ & 0.78 \\
\hline
\end{tabular}

(Continued) 
Table I (Continued).

\begin{tabular}{|c|c|c|c|c|}
\hline Characteristic & Total Sample $N=\mid 64$ & Decision Aid $\mathbf{N}=83$ & eSOC $N=8$ I & $p$-value \\
\hline $\begin{array}{l}\text { Type of substance use disorder } \\
\text { Alcohol use disorder } \\
\text { Opioid use disorder } \\
\text { Cocaine use disorder }\end{array}$ & $\begin{array}{l}23(14.0) \\
151(92.1) \\
69(42.1)\end{array}$ & $\begin{array}{l}14(16.9) \\
76(91.6) \\
32(38.6)\end{array}$ & $\begin{array}{l}9(11.1) \\
75(92.6) \\
37(45.7)\end{array}$ & $\begin{array}{l}0.29 \\
0.81 \\
0.36\end{array}$ \\
\hline $\begin{array}{l}\text { Psychiatric disorders } \\
\text { Bipolar disorder } \\
\text { Anxiety disorder } \\
\text { PTSD } \\
\text { Major depressive disorder }\end{array}$ & $\begin{array}{l}31(18.9) \\
63(38.4) \\
47(28.7) \\
47(28.7)\end{array}$ & $\begin{array}{l}16(19.3) \\
36(43.4) \\
27(32.5) \\
29(34.9)\end{array}$ & $\begin{array}{l}15(18.5) \\
27(33.3) \\
20(24.7) \\
18(22.2)\end{array}$ & $\begin{array}{l}0.90 \\
0.19 \\
0.27 \\
0.07\end{array}$ \\
\hline $\begin{array}{l}\text { Experienced trauma } \\
\text { Physical assault } \\
\text { Assault with weapon } \\
\text { Sexual assault }\end{array}$ & $\begin{array}{l}N=102 \\
68(66.7) \\
29(28.4) \\
53(52.0)\end{array}$ & $\begin{array}{l}N=5 I \\
35(68.6) \\
14(27.5) \\
25(49.0)\end{array}$ & $\begin{array}{l}N=51 \\
33(64.7) \\
15(29.4) \\
28(54.9)\end{array}$ & $\begin{array}{l}0.67 \\
0.83 \\
0.55\end{array}$ \\
\hline $\begin{array}{l}\text { Mean BASIS-24 score (SD) } \\
\text { Overall score } \\
\text { Depression/functioning } \\
\text { Relationships } \\
\text { Self-Harm } \\
\text { Emotional Lability } \\
\text { Psychosis } \\
\text { Substance Abuse }\end{array}$ & $\begin{array}{l}\mathrm{N}=122 \\
1.67(0.75) \\
2.08(1.03) \\
1.56(0.90) \\
0.35(0.64) \\
1.90(1.00) \\
0.53(0.89) \\
2.25(1.13)\end{array}$ & $\begin{array}{l}N=63 \\
1.69(0.74) \\
2.11(1.03) \\
1.68(0.95) \\
0.32(0.55) \\
1.94(0.97) \\
0.49(0.85) \\
2.15(1.13)\end{array}$ & $\begin{array}{l}\mathrm{N}=59 \\
1.65(0.77) \\
2.05(1.53) \\
1.43(0.84) \\
0.38(0.72) \\
1.86(1.00) \\
0.57(0.93) \\
2.36(1.12)\end{array}$ & $\begin{array}{l}0.77 \\
0.74 \\
0.13 \\
0.62 \\
0.67 \\
0.60 \\
0.31\end{array}$ \\
\hline Mean Self-efficacy (SD) & $\begin{array}{l}\mathrm{N}=86 \\
29.1\end{array}$ & $\begin{array}{l}N=44 \\
29.1(6.0)\end{array}$ & $\begin{array}{l}\mathrm{N}=42 \\
29.1\end{array}$ & 0.97 \\
\hline $\begin{array}{l}\text { Mean Social Support score, SD } \\
\text { Main source of social support } \\
\text { Partner } \\
\text { Family } \\
\text { Community/church } \\
\text { Other } \\
\text { No one }\end{array}$ & $\begin{array}{l}73.5(23.7) \\
n=162 \\
49(30.3) \\
67(4 I .4) \\
11(6.8) \\
9(5.6) \\
9(5.6)\end{array}$ & $\begin{array}{l}70.8(25.1) \\
n=82 \\
23(28.1) \\
34(4 I .5) \\
7(8.5) \\
5(6.1) \\
6(7.3)\end{array}$ & $\begin{array}{l}76.3(22.0) \\
n=80 \\
26(32.5) \\
33(41.3) \\
4(5.0) \\
4(5.0) \\
3(3.8)\end{array}$ & $\begin{array}{l}0.14 \\
0.54 \\
0.98 \\
0.53^{\mathrm{a}} \\
1.0 \\
0.50\end{array}$ \\
\hline Mean no. lifetime arrests (SD) & $\begin{array}{l}N=163 \\
3.8(8.8)\end{array}$ & $\begin{array}{l}N=83 \\
4.9(I I .7)\end{array}$ & $\begin{array}{l}N=80 \\
2.7(4.3)\end{array}$ & 0.09 \\
\hline Mean months lifetime incarceration (SD) & $9.6(29.3)$ & $9.5(25.9)$ & $9.7(32.6)$ & 0.95 \\
\hline
\end{tabular}

Note: ${ }^{a}$ Fisher's exact test.

Abbreviations: eSOC, enhanced standard of care; SD, standard deviation; IQR, interquartile range; PTSD, post-traumatic stress disorder; ASI, addiction severity index for psychiatric disorders (-P) and depression (-D).

scale, significantly increasing from before (mean 2.95 [SD 1.2]) to after (mean 3.40 [SD 1.2]; $p=0.003$ ) receiving the DA. The most common factor driving participants' PrEP interest was an understanding from the DA about the PrEP efficacy of preventing HIV, followed by information about side effects, and personal risk.

Use of the PrEP DA significantly transitioned participants along the PrEP care continuum ${ }^{50}$ from interest to action. Over 12 months of follow-up, 18 (10.9\%) women saw a healthcare provider for PrEP, which was significantly higher among women selecting the DA than those who did not $(15.7 \%$ vs $6.2 \% ; p=0.04)$, despite similar levels of HIV risk. Women selecting to use the DA, however, took longer to see a PrEP provider than eSOC participants (mean 32.5 [SD 88.4] vs 11.0 [SD 45.6] days; $p=0.05$ ). There were no significant changes in reported risk behaviors over time for retained participants in either arm. At month 12, participants in the DA arm were somewhat less likely than those in 
Table 2 HIV Risk and PrEP Interest by Study Arm $(\mathrm{N}=164)$

\begin{tabular}{|c|c|c|c|c|}
\hline Characteristic & Total Sample $N=164$ & Decision Aid $\mathbf{N}=83$ & eSOC N=8 I & $p$-value \\
\hline Mean categories HIV risk behaviors (SD) & $2.3(2.0)$ & $2.5(2.1)$ & $2.0(1.8)$ & 0.16 \\
\hline Baseline HIV risk perception for acquiring HIV & $N=155$ & $N=78$ & $N=77$ & \multirow[t]{3}{*}{0.01} \\
\hline Somewhat/extremely likely & $28(18.1)$ & $20(25.6)$ & $8(10.4)$ & \\
\hline Unlikely/not at all & $127(81.9)$ & $58(74.4)$ & $69(89.6)$ & \\
\hline Baseline PrEP eligible & $85(51.8)$ & $47(56.6)$ & $38(46.9)$ & 0.21 \\
\hline Underestimate risk & $58(37.4)$ & $28(35.9)$ & $30(39.0)$ & 0.69 \\
\hline PrEP interest - pre-selection & & & & \multirow[t]{4}{*}{0.05} \\
\hline No & $9(5.5)$ & $\mathrm{I}(\mathrm{I} .2)$ & $8(9.9)$ & \\
\hline Yes & $4 \mathrm{I}(25.0)$ & $21(25.3)$ & $20(24.7)$ & \\
\hline Ambivalent & II4 (69.5) & $61(73.5)$ & $53(65.4)$ & \\
\hline PrEP interest - post-decision aid & $\mathrm{n} / \mathrm{a}$ & & $\mathrm{n} / \mathrm{a}$ & $\mathrm{n} / \mathrm{a}$ \\
\hline Likely/very likely & & $74(89.2)$ & & \\
\hline Unlikely/not at all & & $9(10.8)$ & & \\
\hline Most important factor influenced by decision aid & $\mathrm{n} / \mathrm{a}$ & & $\mathrm{n} / \mathrm{a}$ & \\
\hline Personal risk & & II (6.7) & & \\
\hline Effective at preventing HIV & & $44(26.7)$ & & \\
\hline How it works & & $5(3.0)$ & & \\
\hline Insurance coverage & & I (0.6) & & \\
\hline Side effects & & $11(6.7)$ & & \\
\hline What is involved & & $2(1.2)$ & & \\
\hline Medication interactions & & $6(3.6)$ & & \\
\hline Other & & $3(1.8)$ & & \\
\hline
\end{tabular}

Abbreviation: eSOC, enhanced standard of care.

eSOC to underestimate their HIV risk $(25.0 \%$ vs $32.1 \%$; $p=0.43$ ).

\section{Discussion}

To our knowledge, this is the first reported PrEP DA developed for and tested in women with SUDs in addiction treatment programs. Preliminary findings here suggest that such an aid can have transformative value in accelerating the PrEP care continuum for high-risk women and contribute to the EHE strategy. Important in these findings is that women who (accurately) perceived themselves to be at high-risk for HIV and those with higher alcohol use severity were more likely to opt for a PrEP DA. Though actual and perceived risks were similar between the two groups, those selecting to engage with the DA were more ambivalent about PrEP and engagement with the aid not only substantially increased interest but also resulted in significantly more women starting PrEP.

Health-related decisions emerge from a combination of a person's knowledge and perceptions. Although accurate knowledge may play a large role in patient decisionmaking, its role is variable for some patients and for some decisions. ${ }^{51}$ In terms of the decision to take PrEP, the DA involved a combination of knowledge elements (eg, efficacy at preventing HIV, side effects) and there was a three-fold increase in PrEP interest after using the DA. By building women's knowledge about PrEP, the DA generated interest in PrEP.

Women's decision to receive more information about PrEP through the DA was heavily based on their perceived HIV risk, wherein women in the DA arm more often perceived that they were at-risk for HIV $(25.6 \%$ vs $10.4 \%$ ) and thus could potentially benefit from PrEP. Underestimation of personal risk is common among women at highest risk for HIV. In a survey we did of 125 women on probation or parole, most of whom had SUDs, we found 33\% were clinically eligible for PrEP, but only $17 \%$ perceived they were at risk for HIV. ${ }^{52}$ We also found high rates of risk underestimation among women in prison. $^{53}$ This echoes larger surveys of US women, wherein limited awareness of PrEP and underestimation 
Table 3 Bivariate and Independent Correlates for Selecting for More Information Using a Decision Aid

\begin{tabular}{|c|c|c|c|c|}
\hline \multirow[t]{2}{*}{ Variables } & \multicolumn{2}{|l|}{ Bivariate Analysis } & \multicolumn{2}{|l|}{ Multivariate Analysis } \\
\hline & Decision Aid OR (95\% Cl) & p-value & Decision Aid aOR $(95 \% \mathrm{Cl})$ & p-value \\
\hline Age & $0.99(0.97,1.03)$ & 0.96 & & \\
\hline Race & & 0.69 & & \\
\hline White & REF & & & \\
\hline Black & $0.84(0.36,1.97)$ & & & \\
\hline Other & $1.48(0.50,4.40)$ & & & \\
\hline Hispanic & $1.11(0.41,3.03)$ & 0.84 & & \\
\hline Marital status & & 0.21 & & \\
\hline Married & REF & & & \\
\hline Not/never married & $0.62(0.29, \mathrm{I} .3 \mathrm{I})$ & & & \\
\hline Past 3-year living arrangement & & 0.63 & & \\
\hline Alone & REF & & & \\
\hline Controlled/Unstable & $0.48(0.12,1.98)$ & & & \\
\hline With family/friends & $0.52(0.16,1.62)$ & & & \\
\hline With children/partner & $0.69(0.25,1.94)$ & & & \\
\hline Education completed & & 0.55 & & \\
\hline Less than high school & REF & & & \\
\hline High school & $0.63(0.27,1.47)$ & & & \\
\hline More than high school & $0.77(0.32,1.85)$ & & & \\
\hline Last healthcare provider visit within past year & $0.96(0.45,2.05)$ & 0.91 & & \\
\hline Alcohol use disorder & $1.62(0.66,3.99)$ & 0.29 & & \\
\hline Lifetime severe alcohol use & $3.97(1.07,14.81)$ & 0.04 & $4.13(1.05,16.28)$ & 0.04 \\
\hline Cocaine use disorder & $0.75(0.40,1.39)$ & 0.36 & & \\
\hline Anxiety & $\mathrm{I} .53(0.8 \mathrm{I}, 2.89)$ & 0.19 & $\mathrm{I} .87(0.94,3.70)$ & 0.07 \\
\hline PTSD & $\mathrm{I} .47(0.74,2.91)$ & 0.27 & & \\
\hline BASIS-24 - relationships domain & $1.37(0.94,2.05)$ & 0.13 & & \\
\hline Social support & $0.99(0.98,1.00)$ & 0.14 & $0.99(0.98,1.01)$ & 0.32 \\
\hline Underestimate HIV risk & $0.88(0.46,1.68)$ & 0.69 & & \\
\hline PrEP eligible & $1.48(0.80,2.73)$ & 0.21 & & \\
\hline High perceived HIV risk & $2.97(1.22,7.25)$ & 0.02 & $2.95(1.19,7.35)$ & 0.02 \\
\hline PrEP ambivalence & $1.47(0.75,2.86)$ & 0.26 & & \\
\hline
\end{tabular}

Abbreviations: OR, odds ratio; aOR, adjusted odds ratio; PTSD, post-traumatic stress disorder.

of HIV risk has generated severe under-utilization of PrEP in women. ${ }^{21,54,55}$ Misestimation may result from cognitive biases, including denial and unconscious minimization of risky behaviors in the setting of pervasive loss of autonomy, particularly among women with SUDs.

Reports from DA participants point to yet another dimension of DAs- reorienting personal HIV risk estimation to jumpstart PrEP initiation. Women's realistic self-estimation of HIV risk can be especially challenging because current clinical guidelines for PrEP require women to assess their partner's behaviors (eg, injection drug use, sex with men, etc.), which may be impractical because women's access to this information depends on their partners' disclosures. One alternative strategy is to 
assess external factors, such as personal and partners' criminal justice involvement or intimate partner violence exposure, that have been shown to be associated with incident HIV in women. ${ }^{56-58}$ Still, women may be reluctant to disclose these factors to healthcare providers because of anticipated stigma. Clinicians often underestimate (or do not even consider) women's eligibility for PrEP, even in the most optimistic scenarios when clinicians appropriately enquire about risk and women feel comfortable enough to respond honestly. ${ }^{59,60}$ Therefore, moving the dialogue about PrEP decision-making to a purely objective interface where both risk is assessed and alternatives are presented may help overcome the PrEP delivery gap for women. Such innovations could be enhanced by directing women's DA output to her healthcare provider to extend the dialogue further as part of a shared decision-making process.

The finding that alcohol use severity was associated with women selecting to use the DA is intriguing. Alcohol use is an independent risk factor for HIV, related to intoxication-associated disinhibition, condomless sex, and increased risk-taking. ${ }^{61}$ For PWH, severe alcohol use disorder is associated with delayed HIV diagnosis and reduced treatment engagement and viral suppression, ${ }^{62,63}$ suggesting alcohol use may effect health-related decisionmaking. Conversely, evidence-based treatment of alcohol use disorders with medications (eg naltrexone) is associated with decreased alcohol consumption ${ }^{64}$ and improved HIV treatment outcomes. ${ }^{65}$ While treatment for SUDs has been shown to reduce women's injection-related HIV risk, it has not successfully reduced women's sexrelated HIV risk. ${ }^{66}$ We did not find here that alcohol use severity was associated with HIV risk behaviors. An alternative explanation for how alcohol use severity impacted medical decision-making, and thus interest in receiving more information through the DA, is via alcohol-related neurocognitive impairment (NCI), which is highly prevalent among people with SUDs. ${ }^{67,68}$ We did not directly measure NCI here, but prior studies of people with SUDs at similarly high-risk for HIV have found that NCI was associated with increased interest in an mHealth tool to support PrEP adherence and reinforce risk reduction skills, which has some overlaps with the DA. ${ }^{69}$

Though exploratory in nature due to the sample size, other factors may be important in a woman's decision to select a PrEP DA. For example, in the bivariate analysis, DA participants had higher levels of relationship dysfunction and lower levels of social support, relative to eSOC participants. This finding may suggest that women who are less supported (and thus less exposed to positive peer influence) may seek more intensive information from new sources (like a DA) to make individual decisions about their health. Alternatively, women who experience lower support from family or peers may perceive information from these sources as unreliable and thereby women seek out information from a potentially reputable source like the DA. Relationship factors are especially important for women's medical decision-making and HIV risk because women often experience HIV risk through intimate partners and have overlapping sex and drug use partners that synergistically increases potential exposure to $\mathrm{HIV}^{70}$

Relationship factors influencing DA uptake were also reflected in interpersonal violence exposure. Enrolled participants had extremely high rates of diagnosed PTSD and lifetime trauma that included physical assault, assault with a weapon, and sexual assault. In other samples of men and women with SUD in treatment, $80-92 \%$ report lifetime traumatic experiences and $30-60 \%$ have diagnosed PTSD. ${ }^{71,72}$ Violence exposure broadly impacts women's health-related decision-making, HIV risk, risk perception, and relationship stability. ${ }^{73-75}$ Although we did not explicitly design the DA to be trauma-responsive, we did design it to be women-centered and empowerment oriented, and we used trauma-responsive delivery approaches, including delivering the DA in a closed private setting after building rapport with a single female member of the research team. If the DA is to be more widely disseminated and implemented in treatment settings, it will be important to ensure it is done in a way that is trauma-responsive to meaningfully engage women at highest risk of HIV. We did not find that diagnosed trauma was associated with choosing more information through the DA, though intimate partner violence exposure could have contributed to many of our findings. A principal component or latent class analysis might have better elucidated this factor since intimate partner violence exposure was not explicitly measured here.

This study is not without limitations. It was conducted at a single site in the Northeast US and cannot be fully generalized to all other contexts where resources and PrEP services may differ. Moreover, the sample was limited to women enrolled in addiction treatment, and decisionmaking may differ for women not in treatment who must navigate a myriad of other stressors, including their substance use. Race is an important sociocultural 
consideration in terms of who can access addiction treatment, since non-Hispanic and white women are overrepresented in SUD treatment nationally, as reflected in our sample. Further adaptations may be needed to make the DA more culturally congruent for women who identify as Black and Hispanic. Study arm was allocated by participant preference rather than randomization, which poses two potential biases: 1) unbalanced allocation, which did not occur; and 2) allocation bias, which we did not find to be the case in terms of key demographic and clinical characteristics. There may be unmeasured variables contributing to study arm allocation, though we evaluated the study arm allocation decision as an outcome unto itself as the first step in the decision-making process of PrEP. Some outcomes were self-reported and may have been influenced by social desirability bias. Missingness at random was not formally assessed.

Though we did find that DA participants were significantly more likely to start PrEP, future studies should incorporate a Test and Prevent model where women without HIV are assessed with a DA and linked directly to PrEP services, potentially with patient navigators or other linkage strategies. Although HIV prevention can be incorporated into a broad range of primary care settings, ${ }^{76}$ it is particularly poignant in addiction treatment settings because nearly 1.5 million women access treatment for alcohol or illicit drugs annually ${ }^{77}$ and drug treatment is effective HIV prevention. ${ }^{78}$ A meta-analysis found consistently positive effects of integrated HIV prevention programs into drug treatment settings for knowledge, skills, and behaviors, ${ }^{79}$ supported by recently pooled results across the Clinical Trials Network, ${ }^{80}$ and specifically for women. ${ }^{66}$ Future studies should focus on DA implementation, including integration into the EHR in addiction treatment settings and expanding the DA to include shared decision-making with onsite clinicians. ${ }^{20,81}$ Clinicians in these settings are often not PrEP prescribers but have far more frequent patient contact than prescribers do, including at key touchpoints like treatment entry and repeated treatment planning, which are ideal opportunities for DA delivery.

\section{Conclusions}

The findings support the beneficial effect of a novel PrEP DA on preference for PrEP among women with SUD in treatment, including those experiencing the highest HIV risk. Ideally, the DA tool would be in front of eligible women before they meet clinicians, as this may be a key implementation step. Future research should test this hypothesis.

\section{Data Sharing Statement}

De-identified participant data are available upon reasonable request to the corresponding author, within 5 years of publication.

\section{Funding}

Support for this project was provided by the Doris Duke Charitable Foundation Clinical Scientist Development Award (to JPM). Funding source played no role in data analysis or interpretation or the decision to submit the manuscript for publication.

\section{Disclosure}

Dr Jaimie Meyer reports grants from Gilead Sciences, Inc., outside the submitted work. Dr Glyn Elwyn reports personal fees from EBSCO, during the conduct of the study. Dr Frederick Altice reports grants from NIH, NIDA, SAMHSA, HRSA, Merck, Gilead; also an advisory Board member for Gilead Science, Merck Pharmaceuticals, AbbVie, Alliance for Patient Access; and received Honoraria for speakers bureau from Practice Point Communications, Clinical Care Options, Gilead Science, outside the submitted work. The authors report no other conflicts of interest in this work.

\section{References}

1. Centers for Disease Control. HIV among women; 2016. Available from: http://www.cdc.gov/hiv/group/gender/women/. Accessed September 22, 2016.

2. Collins R, Ellickson P, Orlando M, Klein D. Isolating the nexus of substance use, violence and sexual risk for HIV infection among young adults in the United States. AIDS Behav. 2005;9(1):73-87. doi:10.1007/s10461-005-1683-2

3. Stoner S, Norris J, George W, et al. Women's condom use assertiveness and sexual risk-taking: effects of alcohol intoxication and adult victimization. Addict Behav. 2008;33(9):1167-1176. doi:10.1016/j. addbeh.2008.04.017

4. Seth P, Wingood GM, DiClemente RJ, Robinson LS. Alcohol use as a marker for risky sexual behaviors and biologically confirmed sexually transmitted infections among young adult African-American women. Womens Health Issues. 2011;21(2):130-135. doi:10.1016/j. whi.2010.10.005

5. World Health Organization. Consolidated Guidelines on HIV Prevention, Diagnosis, Treatment, and Care for Key Populations. Geneva, Switzerland: World Health Organization; 2014.

6. The White House Office of National AIDS Policy. National HIV/AIDS Strategy for the United States: Updated to 2020. Washington, D.C.: Health Resources and Services Administration; 2015.

7. HIV.gov. Ending the HIV epidemic: a plan for America; 2019. Available from: https://www.hiv.gov/federal-response/ending-the-hivepidemic/overview. Accessed September 23, 2019. 
8. Chen N, Meyer J, Springer S. Advances in the prevention of heterosexual transmission of HIV/AIDS among women in the United States. Infect Dis Rep. 2011;3(1):e6. doi:10.4081/idr.2011.2362

9. Blankenship KM, Reinhard E, Sherman SG, El-Bassel N. Structural interventions for HIV prevention among women who use drugs: a global perspective. J Acquir Immune Defic Syndr. 2015;69(Suppl 2):S140-S145. doi:10.1097/QAI.0000000000000638

10. Office of Research on Women's Health. Moving into the future with new dimensions and strategies: a vision for 2020 for women's health research. 2010.

11. Wizeman T, Pardue M. Exploring the biological contributions to human health: does sex matter? Washington, DC. 2001.

12. Seidman D, Weber S. Integrating preexposure prophylaxis for human immunodeficiency virus prevention into women's health care in the United States. Obstet Gynecol. 2016;128(1):37-43. doi:10.1097/ AOG.0000000000001455

13. Stein ZA. HIV prevention: the need for methods women can use. $A m$ J Public Health. 1990;80(4):460-462. doi:10.2105/AJPH.80.4.460

14. Abdool Karim Q, Abdool Karim SS, Frohlich JA, et al. Effectiveness and safety of tenofovir gel, an antiretroviral microbicide, for the prevention of HIV infection in women. Science. 2010;329 (5996):1168-1174. doi:10.1126/science. 1193748

15. Baeten JM, Donnell D, Ndase P, et al. Antiretroviral prophylaxis for HIV prevention in heterosexual men and women. $N$ Engl $\mathrm{J} \mathrm{Med}$. 2012;367(5):399-410. doi:10.1056/NEJMoa1108524

16. Thigpen MC, Kebaabetswe PM, Paxton LA, et al. Antiretroviral preexposure prophylaxis for heterosexual HIV transmission in Botswana. $N$ Engl J Med. 2012;367(5):423-434. doi:10.1056/ NEJMoa1110711

17. Hanscom B, Janes HE, Guarino PD, et al. Brief report: preventing HIV-1 infection in women using oral preexposure prophylaxis: a meta-analysis of current evidence. J Acquir Immune Defic Syndr. 2016;73(5):606-608. doi:10.1097/QAI.0000000000001160

18. Supervie V, Barrett M, Kahn JS, et al. Modeling dynamic interactions between pre-exposure prophylaxis interventions \& treatment programs: predicting HIV transmission \& resistance. Sci Rep. 2011;1:185. doi:10.1038/srep00185

19. Choopanya K, Martin M, Suntharasamai P, et al. Antiretroviral prophylaxis for HIV infection in injecting drug users in Bangkok, Thailand (the Bangkok Tenofovir Study): a randomised, double-blind, placebo-controlled Phase 3 trial. Lancet. 2013;381 (9883):2083-2090. doi:10.1016/S0140-6736(13)61127-7

20. Page K, Tsui J, Maher L, et al. Biomedical HIV prevention including pre-exposure prophylaxis and opiate agonist therapy for women who inject drugs: state of research and future directions. J Acquir Immune Defic Syndr. 2015;69(Suppl 2):S169-S175. doi:10.1097/ QAI.0000000000000641

21. Wingood GM, Dunkle K, Camp C, et al. Racial differences and correlates of potential adoption of preexposure prophylaxis: results of a national survey. J Acquir Immune Defic Syndr. 2013;63(Suppl 1): S95-S101. doi:10.1097/QAI.0b013e3182920126

22. Garnett GP, Hallett TB, Takaruza A, et al. Providing a conceptual framework for HIV prevention cascades and assessing feasibility of empirical measurement with data from east Zimbabwe: a case study. Lancet HIV. 2016;3(7):e297-e306. doi:10.1016/S2352-3018(16) 30039-X

23. Elopre L, Kudroff K, Westfall AO, Overton ET, Mugavero MJ. The right people, right places, and right practices: disparities in PrEP access among African American men, women and MSM in the deep south. J Acquir Immune Defic Syndr. 2016;74(1):56.

24. Garfinkel DB, Alexander KA, McDonald-Mosley R, Willie TC, Decker MR. Predictors of HIV-related risk perception and PrEP acceptability among young adult female family planning patients. AIDS Care. 2016;29:1-8.
25. Auerbach JD, Kinsky S, Brown G, Charles V. Knowledge, attitudes, and likelihood of pre-exposure prophylaxis (PrEP) use among US women at risk of acquiring HIV. AIDS Patient Care STDS. 2015;29 (2):102-110. doi:10.1089/apc.2014.0142

26. Jayakumaran JS, Aaron E, Gracely EJ, Schriver E, Szep Z, Clark JL. Knowledge, attitudes, and acceptability of pre-exposure prophylaxis among individuals living with HIV in an urban HIV clinic. PLoS One. 2016;11(2):e0145670. doi:10.1371/journal.pone.0145670

27. Koechlin FM, Fonner VA, Dalglish SL, et al. Values and preferences on the use of oral Pre-exposure Prophylaxis (PrEP) for HIV prevention among multiple populations: a systematic review of the literature. AIDS Behav. 2016;21:1-11.

28. Shrestha R, Karki P, Altice FL, et al. Correlates of willingness to initiate pre-exposure prophylaxis and anticipation of practicing safer drug- and sex-related behaviors among high-risk drug users on methadone treatment. Drug Alcohol Depend. 2017;173:107-116. doi:10.1016/j.drugalcdep.2016.12.023

29. Smith DK, Van Handel M, Wolitski RJ, et al. Vital signs: estimated percentages and numbers of adults with indications for preexposure prophylaxis to prevent HIV acquisition-United States, 2015. MMWR Morb Mortal Wkly Rep. 2015;64(46):1291-1295. doi:10.15585/ mmwr.mm6446a4

30. Iversen J, Page K, Madden A, Maher L. HIV, HCV, and health-related harms among women who inject drugs: implications for prevention and treatment. J Acquir Immune Defic Syndr. 2015;69 (Suppl 2):S176-S181. doi:10.1097/QAI.0000000000000659

31. Mera R, McCallister S, Palmer B, Mayer G, Mangnuson D, Rawlings K. Abstract TUAX0105LB: FTC/TDF (Truvada) for HIV pre-exposure prophylaxis (PrEP) utilization in the United States: 2013-2015. 21st International AIDS Conference; 2016; Durban, South Africa.

32. Sewell WC, Solleveld P, Seidman D, Dehlendorf C, Marcus JL, Krakower DS. Patient-led decision-making for HIV preexposure prophylaxis. Curr HIV/AIDS Rep. 2021;18(1):48-56. doi:10.1007/ s11904-020-00535-w

33. Stacey D, Legare F, Col NF, et al. Decision aids for people facing health treatment or screening decisions. Cochrane Database Syst Rev. 2014;(1):Cd001431. doi:10.1002/14651858.CD001431.pub4

34. Powell V, Mayer K, Maloney K, Wong J, Wilson I, Krakower D. Impact of a clinical decision aid for prescribing HIV preexposure prophylaxis to men who have sex with men on primary care provider knowledge and intentions. International Conference on HIV Treatment and Prevention Adherence; 2018; Miami, FL.

35. Krakower D, Powell V, Maloney K, Wong J, Wilson I, Mayer K. Impact of a personalized clinical decision aid on informed decision-making about HIV preexposure prophylaxis among men who have sex with men. International Conference on HIV Treatment and Prevention Adherence; 2018; Miami, FL.

36. Madden LM, Farnum SO, Eggert KF, et al. An investigation of an open-access model for scaling up methadone maintenance treatment. Addiction. 2018;113(8):1450-1458. doi:10.1111/add.14198

37. Qin Y, Price C, Rutledge R, Puglisi L, Madden LM, Meyer JP. Women's decision-making about PrEP for HIV prevention in drug treatment contexts. $J$ Int Assoc Provid AIDS Care. 2020;19:2325958219900091. doi:10.1177/2325958219900091

38. Elwyn G, O'Connor A, Stacey D, et al. Developing a quality criteria framework for patient decision aids: online international Delphi consensus process. BMJ. 2006;333(7565):417. doi:10.1136/bmj.38926.629329.AE

39. Gray MJ, Litz BT, Hsu JL, Lombardo TW. Psychometric properties of the life events checklist. Assessment. 2004;11(4):330-341. doi:10.1177/1073191104269954

40. Eisen SV, Normand SL, Belanger AJ, Spiro A, Esch D. The revised Behavior and Symptom Identification Scale (BASIS-R): reliability and validity. Med Care. 2004;42(12):1230-1241. doi:10.1097/ 00005650-200412000-00010 
41. Schwarzer R, Jerusalemn M. Generalized self-efficacy scale. In: Weinman J, Wright S, Johnston M, editors. Measures in Health Psychology: A User's Portfolio. Causal and Control Beliefs. Windsor, UK: NFER-NELSON; 1995:35-37.

42. Rosen C, Henson B, Finney J, Moos R. Consistency of self-administered and interview-based addiction severity index composite scores. Addiction. 2000;95(3):419-425. doi:10.1046/j.13600443.2000.95341912.x

43. Reinert D, Allen J. The Alcohol Use Disorders Identification Test (AUDIT): a review of recent research. Alcohol Clin Exp Res. 2002;26 (2):272-279. doi:10.1111/j.1530-0277.2002.tb02534.x

44. O'Connor EA, Perdue LA, Senger CA, et al. Screening and behavioral counseling interventions to reduce unhealthy alcohol use in adolescents and adults: updated evidence report and systematic review for the US preventive services task force. JAMA. 2018;320 (18):1910-1928. doi:10.1001/jama.2018.12086

45. McLellan AT, Kushner H, Metzger D, et al. The fifth edition of the addiction severity index. J Subst Abuse Treat. 1992;9(3):199-213.

46. Fisher JD, Fisher WA, Cornman DH, Amico RK, Bryan A, Friedland GH. Clinician-delivered intervention during routine clinical care reduces unprotected sexual behavior among HIV-infected patients. $J$ Acquir Immune Defic Syndr. 2006;41(1):44-52. doi:10.1097/01.qai.0000192000.15777.5c

47. Centers for Disease Control and Prevention. Preexposure prophylaxis for the prevention of HIV infection - 2014: a clinical practice guideline. Available from: http://stacks.cdc.gov/view/cdc/231092014. Accessed September 23, 2019.

48. Centers for Disease Control and Prevention. Preexposure prophylaxis for the prevention of HIV infection in the United States- 2017 update, a clinical practice guideline; 2018. Available from: https://www.cdc.gov/ hiv/pdf/risk/prep/cdc-hiv-prep-guidelines-2017.pdf. Accessed August 12, 2021.

49. Substance Abuse and Mental Health Services Administration. 2016 National Survey on Drug Use and Health. Rockville, Maryland: Substance Abuse and Mental Health Services Administration; 2017.

50. Nunn AS, Brinkley-Rubinstein L, Oldenburg CE, et al. Defining the HIV pre-exposure prophylaxis care continuum. AIDS. 2017;31 (5):731-734. doi:10.1097/QAD.0000000000001385

51. Williams N, Kogan R. Factors associated with evidence-based decision-making among patients and providers. J Comp Eff Res. 2019;8(9):709-719. doi:10.2217/cer-2018-0152

52. Rutledge R, Madden L, Ogbuagu O, Meyer JP. HIV risk perception and eligibility for pre-exposure prophylaxis in women involved in the criminal justice system. AIDS Care. 2018;30:1-8.

53. PrEP Eligibility and HIV Risk Perception for Women across the Criminal Justice Continuum in Connecticut. 12th Academic and Health Policy on Conference on Correctional Health. Las Vegas, Nevada. March 2019.

54. Huang Y-LA, Zhu W, Smith DK, Harris N, Hoover KW. HIV preexposure prophylaxis, by race and ethnicity - United States, 20142016. MMWR Morb Mortal Wkly Rep. 2018;67(41):1147-1150. doi:10.15585/mmwr.mm6741a3

55. Mera Giler R, Magnuson D, Trevor H, Bush S, Rawlings K, McCallister S. WEPEC0919: changes in truvada (TVD) for HIV preexposure prophylaxis (PreP) utilization in the United States: 20122016. International AIDS Society Conference; 2017; Paris, France.

56. Knittel AK, Lambdin BH, Comfort ML, Kral AH, Lorvick J. Sexual risk and criminal justice involvement among women who use drugs. AIDS Behav. 2019;23(12):3366-3374. doi:10.1007/s10461-01902447-2

57. Knittel AK, Shook-Sa BE, Rudolph J, et al. Incarceration and number of sexual partners after incarceration among vulnerable US women, 2007-2017. Am J Public Health. 2020;110(S1):S100-S108. doi:10.2105/AJPH.2019.305410
58. Sareen J, Pagura J, Grant B. Is intimate partner violence associated with HIV infection among women in the United States? Gen Hosp Psychiatry. 2009;31(3):274-278. doi:10.1016/j.genhosppsych.2009.02.004

59. Calabrese SK, Willie TC, Galvao RW, et al. Current US guidelines for prescribing HIV Pre-Exposure Prophylaxis (PrEP) disqualify many women who are at risk and motivated to use PrEP. J Acquir Immune Defic Syndr. 2019;81:395-405. doi:10.1097/QAI.0000000000002042

60. Bradley ELP, Hoover KW. Improving HIV preexposure prophylaxis implementation for women: summary of key findings from a discussion series with women's HIV prevention experts. Womens Health Issues. 2019;29(1):3-7. doi:10.1016/j.whi.2018.08.004

61. Shuper PA, Neuman M, Kanteres F, Baliunas D, Joharchi N, Rehm J. Causal considerations on alcohol and HIV/AIDS-a systematic review. Alcohol Alcohol. 2010;45(2):159-166. doi:10.1093/alcalc/ agp091

62. Azar MM, Springer SA, Meyer JP, Altice FL. A systematic review of the impact of alcohol use disorders on HIV treatment outcomes, adherence to antiretroviral therapy and health care utilization. Drug Alcohol Depend. 2010;112:178-193. doi:10.1016/j. drugalcdep.2010.06.014

63. Wagman JA, Wynn A, Matsuzaki M, et al. Hazardous alcohol use, antiretroviral therapy receipt, and viral suppression in people living with HIV who inject drugs in the United States, India, Russia, and Vietnam. AIDS. 2020;34(15):2285-2294. doi:10.1097/ QAD.0000000000002716

64. Springer SA, Di Paola A, Azar MM, Barbour R, Krishnan A, Altice FL. Extended-release naltrexone reduces alcohol consumption among released prisoners with HIV disease as they transition to the community. Drug Alcohol Depend. 2017;174:158-170. doi:10.1016/j. drugalcdep.2017.01.026

65. Springer SA, Di Paola A, Azar M, et al. Extended-release naltrexone improves viral suppression among incarcerated persons living with HIV with opioid use disorders transitioning to the community: results of a double-blind, placebo-controlled randomized trial. J Acquir Immune Defic Syndr. 2018;78:43.

66. Tross S, Campbell AN, Cohen LR, et al. Effectiveness of HIV/STD sexual risk reduction groups for women in substance abuse treatment programs: results of NIDA Clinical Trials Network Trial. J Acquir Immune Defic Syndr. 2008;48(5):581-589. doi:10.1097/ QAI.0b013e31817efb6e

67. Shrestha R, Weikum D, Copenhaver M, Altice FL. The influence of neurocognitive impairment, depression, and alcohol use disorders on health-related quality of life among incarcerated, HIV-infected, opioid dependent Malaysian men: a moderated mediation analysis. AIDS Behav. 2017;21(4):1070-1081. doi:10.1007/s10461-016-1526-3

68. Arias F, Arnsten JH, Cunningham CO, et al. Neurocognitive, psychiatric, and substance use characteristics in opioid dependent adults. Addict Behav. 2016;60:137-143. doi:10.1016/j.addbeh.2016.03.018

69. Shrestha R, Huedo-Medina TB, Altice FL, Krishnan A, Copenhaver M. Examining the acceptability of mHealth technology in HIV prevention among high-risk drug users in treatment. AIDS Behav. 2017;21(11):3100-3110. doi:10.1007/s10461-016-1637-x

70. El-Bassel N, Wechsberg WM, Shaw SA. Dual HIV risk and vulnerabilities among women who use or inject drugs: no single prevention strategy is the answer. Curr Opin HIV AIDS. 2012;7(4):326-331. doi:10.1097/COH.0b013e3283536ab2

71. Dore G, Mills K, Murray R, Teesson M, Farrugia P. Post-traumatic stress disorder, depression and suicidality in inpatients with substance use disorders. Drug Alcohol Rev. 2012;31(3):294-302. doi:10.1111/ j.1465-3362.2011.00314.x

72. Mills KL, Lynskey M, Teesson M, Ross J, Darke S. Post-traumatic stress disorder among people with heroin dependence in the Australian treatment outcome study (ATOS): prevalence and correlates. Drug Alcohol Depend. 2005;77(3):243-249. doi:10.1016/ j.drugalcdep.2004.08.016 
73. Willie TC, Keene DE, Kershaw TS, Stockman JK. "You never know what could happen": women's perspectives of pre-exposure prophylaxis in the context of recent intimate partner violence. Womens Health Issues. 2020;30(1):41-48. doi:10.1016/j. whi.2019.08.001

74. Singer M. AIDS and the health crisis of the U.S. urban poor; the perspective of critical medical anthropology. Soc Sci Med. 1994;39 (7):931-948. doi:10.1016/0277-9536(94)90205-4

75. Meyer JP, Springer SA, Altice FL. Substance abuse, violence, and HIV in women: a literature review of the syndemic. $J$ Womens Health (Larchmt). 2011;20(7):991-1006. doi:10.1089/jwh.2010.2328

76. Mathers BM, Cooper DA. Integrating HIV prevention into practice. JAMA. 2014;312(4):349-350. doi:10.1001/jama.2014.8606

77. Substance Abuse and Mental Health Services Administration Center for Behavioral Health Statistics and Quality. Behavioral Health Trends in the United States: Results from the 2014 National Survey on Drug Use and Health. Substance Abuse and Mental Health Services Administration Center; 2015.
78. Springer SA, Larney S, Alam-Mehrjerdi Z, Altice FL, Metzger D, Shoptaw S. Drug treatment as HIV prevention among women and girls who inject drugs from a global perspective: progress, gaps, and future directions. J Acquir Immune Defic Syndr. 2015;69(Suppl 2): S155-S161. doi:10.1097/QAI.0000000000000637

79. Prendergast ML, Urada D, Podus D. Meta-analysis of HIV risk-reduction interventions within drug abuse treatment programs. J Consult Clin Psychol. 2001;69(3):389-405. doi:10.1037/0022006X.69.3.389

80. Crits-Christoph P, Gallop R, Sadicario JS, et al. Predictors and moderators of outcomes of HIV/STD sex risk reduction interventions in substance abuse treatment programs: a pooled analysis of two randomized controlled trials. Subst Abuse Treat Prev Policy. 2014;9:3. doi:10.1186/1747-597X-9-3

81. El-Bassel N, Strathdee SA. Women who use or inject drugs: an action agenda for women-specific, multilevel, and combination HIV prevention and research. J Acquir Immune Defic Syndr. 2015;69(Suppl 2): S182-S190. doi:10.1097/QAI.0000000000000628
Patient Preference and Adherence

\section{Publish your work in this journal}

Patient Preference and Adherence is an international, peer-reviewed, open access journal that focusing on the growing importance of patient preference and adherence throughout the therapeutic continuum. Patient satisfaction, acceptability, quality of life, compliance, persistence and their role in developing new therapeutic modalities and compounds to optimize clinical outcomes for existing disease

\section{Dovepress}

states are major areas of interest for the journal. This journal has been accepted for indexing on PubMed Central. The manuscript management system is completely online and includes a very quick and fair peer-review system, which is all easy to use. Visit http:// www.dovepress.com/testimonials.php to read real quotes from published authors. 